\title{
Frustrated Magnetism in a 2-D Ytterbium Fluoride
}

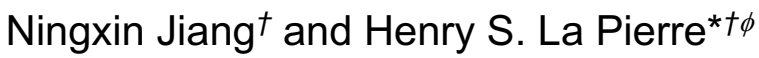 \\ †School of Chemistry and Biochemistry and the ${ }^{\Uparrow}$ Nuclear and Radiological \\ Engineering Program, Georgia Institute of Technology, Atlanta, Georgia \\ 30332-0400, United States \\ *hsl@gatech.edu
}

\section{Table of contents}

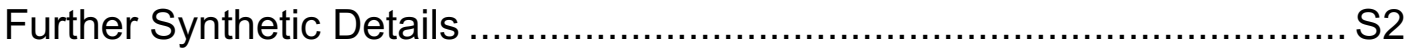

Single crystal X-ray diffraction and analysis ......................................... 22

Powder X-ray diffraction (PXRD) ...................................................... 7

Fourier-transformation infrared spectroscopy (FT-IR) ........................... S8

Physical property measurements .................................................. 9

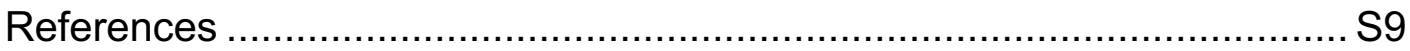




\section{Further Synthetic Details}

General methods. All reagents were obtained from commercial suppliers without further purification. Deionized water with a resistivity of $18.2 \mathrm{M} \Omega \cdot \mathrm{cm}$ was used for all syntheses. Hydrothermal reactions were carried out in $23 \mathrm{~mL}$ Teflon-lined pressure vessels (Parr 4749).

Table S1. List of control experiments for the synthesis of 1-Yb. ${ }^{a}$

\begin{tabular}{|c|c|c|c|c|}
\hline $\begin{array}{l}\text { Experiment } \\
\text { number. }\end{array}$ & $\begin{array}{l}\mathrm{m}_{\mathrm{Yb}\left(\mathrm{NO}_{3}\right)_{3}} \\
(\mathrm{mmol})\end{array}$ & $\begin{array}{l}\mathrm{m}_{\mathrm{H}_{2} \mathrm{SO}_{4}} \\
(\mathrm{mmol})\end{array}$ & $\begin{array}{l}\text { Reaction products } \\
\text { (identified by PXRD) }\end{array}$ & Notes \\
\hline 1 & 1.0 & 3.9 & $1-\mathrm{Yb}, \mathrm{KYb}_{3} \mathrm{~F}_{10}$ & \\
\hline 2 & 1.0 & 11.8 & $1-Y b$ & $\begin{array}{l}\text { Crystals are too } \\
\text { small for SCXRD }\end{array}$ \\
\hline 3 & 1.0 & 15.7 & $1-\mathrm{Yb}, \mathrm{YbF}_{3}$ & \\
\hline 4 & 1.0 & 31.4 & $\mathrm{YbF}_{3}$ & \\
\hline 5 & 2.0 & 2.0 & $1-\mathrm{Yb}, \mathrm{YbF}_{3}$ & \\
\hline 6 & 2.0 & 3.9 & $1-\mathrm{Yb}, \mathrm{YbF}_{3}$ & \\
\hline 7 & 2.0 & 7.8 & $1-Y b$ & $\begin{array}{l}\text { Crystals are too } \\
\text { small for SCXRD }\end{array}$ \\
\hline 8 & 2.0 & 15.7 & $1-Y b$ & $\begin{array}{l}\text { Reaction condition } \\
\text { used in this work }\end{array}$ \\
\hline
\end{tabular}

${ }^{a}$ All the control experiments use $5.0 \mathrm{mmol} \mathrm{KF}$ and $4.0 \mathrm{~mL}$ deionized water. The mixture was all sealed in stainless-steel Parr vessel equipped with $23 \mathrm{~mL}$ Teflon liner and reacted in preheated oven at $230^{\circ} \mathrm{C}$ for 18 hours.

\section{Single crystal X-ray diffraction and analysis}

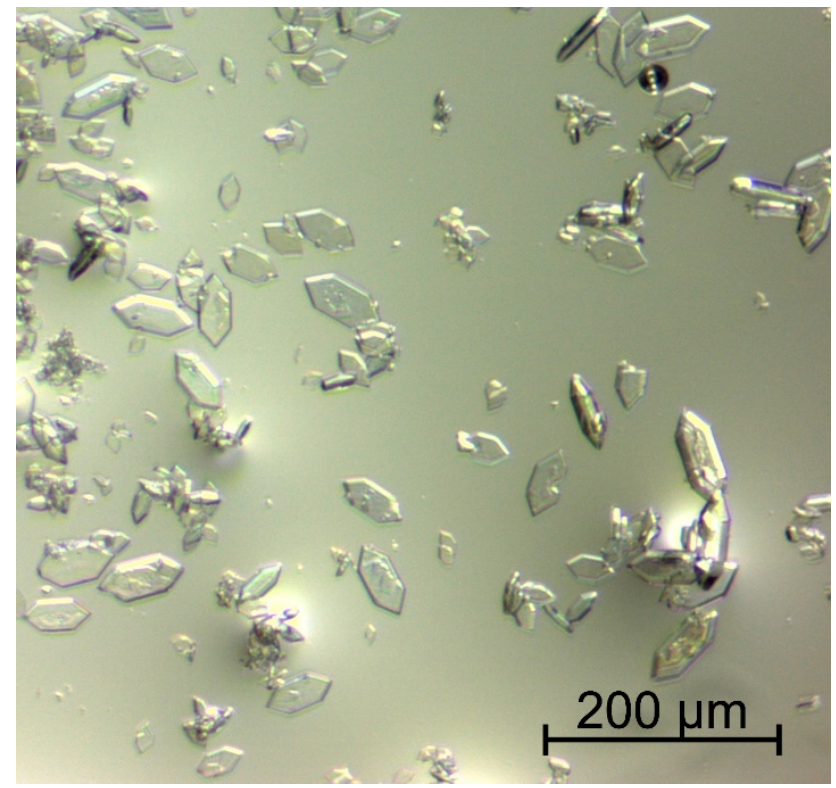

Figure S1. Crystals of $\mathrm{KYb}_{2} \mathrm{~F}_{5} \mathrm{SO}_{4}$ in paratone oil under optical microscope 
Crystallographic Analyses. A single crystal of $\mathrm{KYb}_{2} \mathrm{~F}_{5} \mathrm{SO}_{4}$ was mounted on a loop with paratone oil. The crystals were cooled and kept at $T=100(2) \mathrm{K}$ during the data collection. The crystals were then optically aligned on a Bruker D8 Quest X-ray diffractometer using a digital camera. Diffraction data were obtained by irradiating the crystals with an X-ray source (Mo Ka, $\lambda=0.71073 \AA$ ) with high brilliance and highperformance focusing multilayered optics. APEX 3 was used for determination of the unit cells, data collection, and integration of the data. Numerical absorption corrections were also applied with SADABS. ${ }^{1}$ A quarter sphere of data was collected for all crystals. The structure was solved with the ShelXT structure solution program using the Intrinsic Phasing solution method and by using Olex2 as the graphical interface. ${ }^{2}$ The model was refined with version 2014/7 of ShelXL2014 using Least Squares minimization. ${ }^{3}$ 
Table S2. Crystal data and structure refinement for $\mathrm{KYb}_{2} \mathrm{~F}_{5} \mathrm{SO}_{4}$

\begin{tabular}{|c|c|}
\hline Compound & $\mathrm{KYb}_{2} \mathrm{~F}_{5} \mathrm{SO}_{4}$ \\
\hline Empirical formula & $\mathrm{KYb}_{2} \mathrm{~F}_{5} \mathrm{SO}_{4}$ \\
\hline$D_{\text {calc. }} / \mathrm{g} \mathrm{cm}^{-3}$ & 5.705 \\
\hline$m / \mathrm{mm}^{-1}$ & 28.719 \\
\hline Formula Weight & 576.24 \\
\hline Color & colorless \\
\hline Shape & Prism \\
\hline Size $/ \mathrm{mm}^{3}$ & $0.128 \times 0.064 \times 0.063$ \\
\hline$T / \mathrm{K}$ & $100(2)$ \\
\hline Crystal System & Orthorhombic \\
\hline Space Group & Pbcm \\
\hline a / $\AA$ & $6.4616(14)$ \\
\hline$b / \AA$ & $13.292(4)$ \\
\hline$c / \AA$ & $7.8111(18)$ \\
\hline$\alpha I^{\circ}$ & 90 \\
\hline$\beta /^{\circ}$ & 90 \\
\hline$y 1^{\circ}$ & 90 \\
\hline $\mathrm{V} / \AA^{3}$ & $670.9(3)$ \\
\hline$Z$ & 4 \\
\hline$Z^{\prime}$ & 0.5 \\
\hline$F(000)$ & 1008 \\
\hline Radiation & $\operatorname{MoKa}(\lambda=0.71073)$ \\
\hline $2 \theta$ range for data collection( $\left(^{\circ}\right)$ & 6.306 to 66.328 \\
\hline Index Ranges & $-9 \leq h \leq 9,-20 \leq k \leq 20,-11 \leq 1 \leq 12$ \\
\hline Reflections Collected & 10025 \\
\hline Independent Reflections & $1356\left[R_{\text {int }}=0.0610, R_{\text {sigma }}=0.0383\right]$ \\
\hline Data/Restraints/Parameters & $1356 / 0 / 72$ \\
\hline Goodness-of-Fit on F2 & 1.111 \\
\hline Final R Indexes [I>=2 $\sigma(\mathrm{I})]$ & $\mathrm{R} 1=0.0210, w R 2=0.0529$ \\
\hline Final R Indexes [all data] & $\mathrm{R} 1=0.0216, w R 2=0.0533$ \\
\hline Largest Diff. Peak/Hole (e / $\left.\AA^{3}\right)$ & $2.21 /-1.79$ \\
\hline Completeness to $2 \theta$ & $100 \%$ \\
\hline
\end{tabular}


Table S3. Atomic coordinates

\begin{tabular}{llllll}
\hline Atoms & $\begin{array}{l}\text { Wyckoff } \\
\text { position }\end{array}$ & $x / a$ & $y / b$ & $z / c$ & $U_{\text {eq }}$ \\
& $4 d$ & $0.15834(3)$ & $0.20591(2)$ & $1 / 4$ & $0.00424(7)$ \\
Yb1 & $4 c$ & $0.64022(3)$ & $1 / 4$ & $1 / 2$ & $0.00433(7)$ \\
Yb2 & $4 d$ & $0.38709(16)$ & $0.49834(9)$ & $1 / 4$ & $0.01202(19)$ \\
K1 & $4 d$ & $0.87957(17)$ & $0.43329(9)$ & $1 / 4$ & $0.00510(19)$ \\
S1 & $4 d$ & $0.9316(5)$ & $0.5413(3)$ & $1 / 4$ & $0.0072(6)$ \\
O1 & $4 d$ & $0.0755(5)$ & $0.3761(3)$ & $1 / 4$ & $0.0066(6)$ \\
O2 & $8 e$ & $0.7570(4)$ & $0.5920(2)$ & $0.0953(3)$ & $0.0072(4)$ \\
O3 & $4 c$ & $0.0197(5)$ & $1 / 4$ & 0 & $0.0071(5)$ \\
F1 & $4 d$ & $0.4566(4)$ & $0.2951(2)$ & $1 / 4$ & $0.0073(5)$ \\
F2 & $8 e$ & $0.3900(3)$ & $0.14377(17)$ & $0.4313(2)$ & $0.0078(4)$ \\
F3 & $4 d$ & $0.7888(5)$ & $0.3045(2)$ & $3 / 4$ & $0.0067(5)$ \\
F4 & & & & & \\
\hline
\end{tabular}

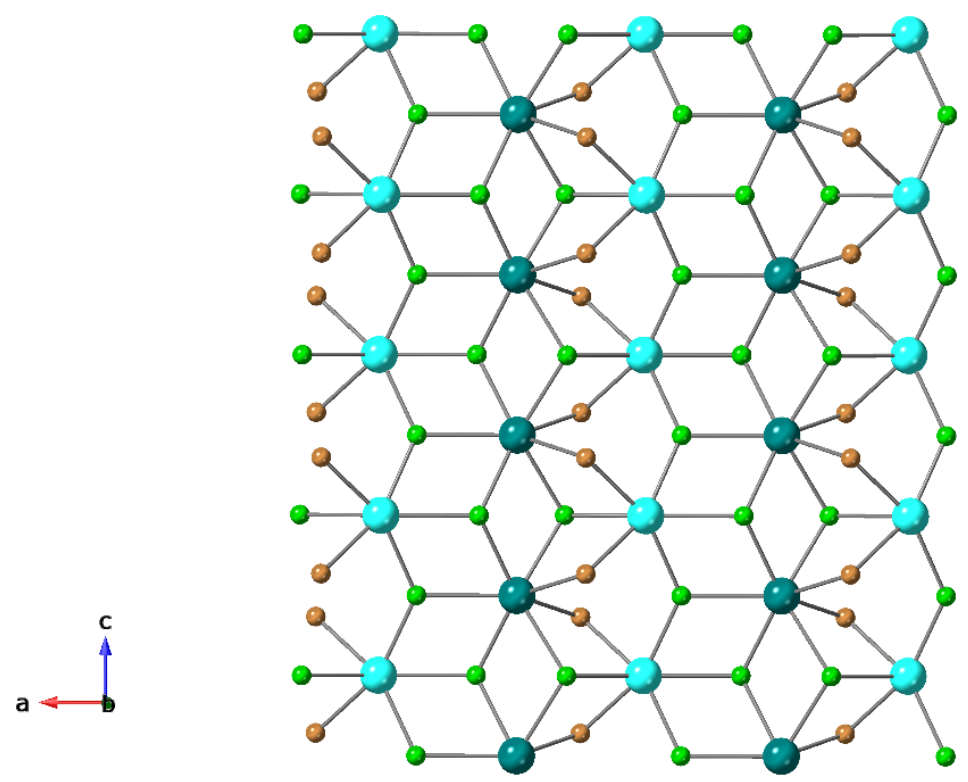

Figure S2. Demonstration of fluoride bridging mode in 1-Yb. The fluorine atoms with $\mu_{2}$ bridging mode are brown and fluorine atoms with $\mu_{3}$ bridging mode are green. 


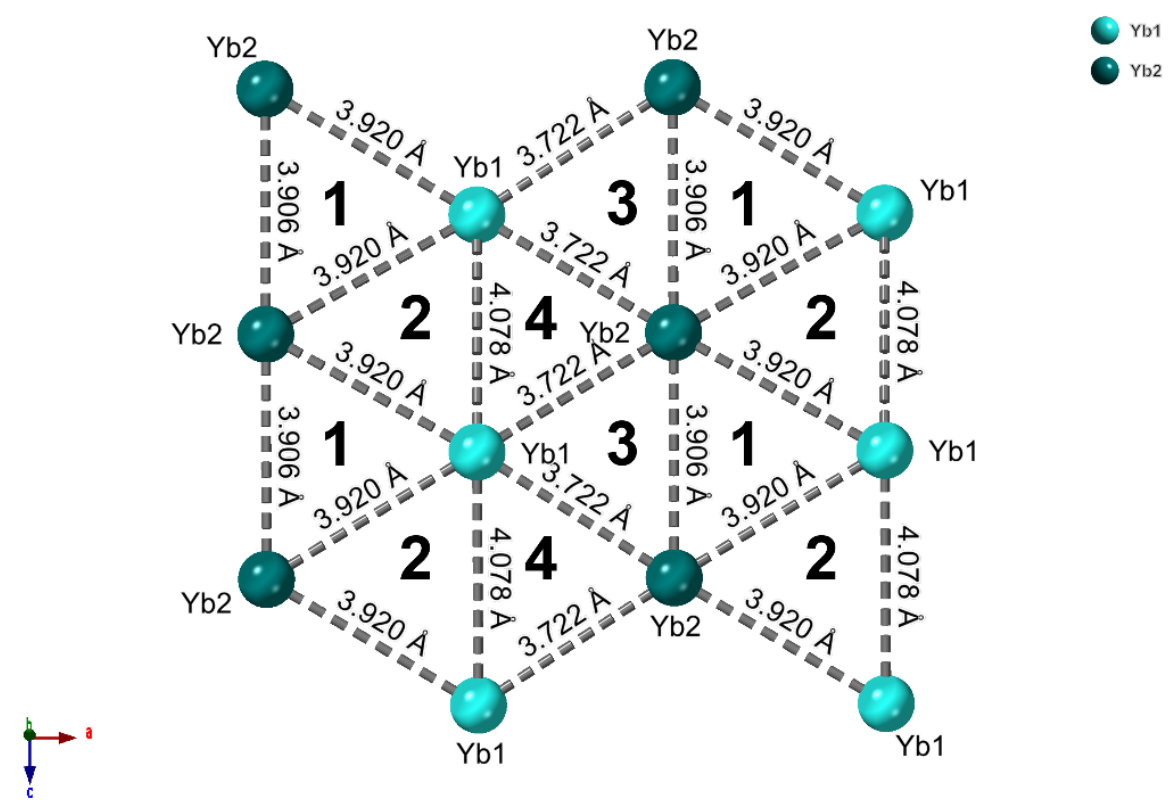

Figure S3. Demonstration of four different triangles in 1-Yb. These four types of triangles are designated as triangle 1, 2, 3 and 4, and number in the center of each triangles indicate the type of the triangle. 
Table S4. Internal angles of four types of triangles in 1-Yb.

\begin{tabular}{|c|c|c|c|c|c|c|}
\hline $\begin{array}{l}\text { Tria } \\
\text { ngle }\end{array}$ & Angle 1 & Degree $/^{\circ}$ & Angle 2 & Degree $/^{\circ}$ & Angle 3 & $\begin{array}{l}\text { Degree } \\
1^{\circ}\end{array}$ \\
\hline 1 & $\begin{array}{l}\angle \mathrm{Yb} 2-\mathrm{Yb} 1- \\
\mathrm{Yb} 2\end{array}$ & $59.759(16)$ & $\begin{array}{l}\angle \mathrm{Yb} 1-\mathrm{Yb} 2- \\
\mathrm{Yb} 2\end{array}$ & $60.120(8)$ & $\begin{array}{l}\angle \mathrm{Yb} 1-\mathrm{Yb} 2- \\
\mathrm{Yb} 2\end{array}$ & $60.120(8)$ \\
\hline 2 & $\begin{array}{l}\angle \mathrm{Yb} 1-\mathrm{Yb} 2- \\
\mathrm{Yb} 1\end{array}$ & $62.682(16)$ & $\begin{array}{l}\angle \mathrm{Yb} 1-\mathrm{Yb} 1- \\
\mathrm{Yb} 2\end{array}$ & $9(8)$ & $\begin{array}{l}\angle \mathrm{Yb} 1-\mathrm{Yb} 1- \\
\mathrm{Yb} 2\end{array}$ & $59(8)$ \\
\hline 3 & $\begin{array}{l}\angle \mathrm{Yb} 2-\mathrm{Yb} 1- \\
\mathrm{Yb} 2\end{array}$ & $63.294(17)$ & $\begin{array}{l}\angle \mathrm{Yb} 1-\mathrm{Yb} 2- \\
\mathrm{Yb} 2\end{array}$ & $58.353(8)$ & $\begin{array}{l}\angle \mathrm{Yb} 1-\mathrm{Yb} 2- \\
\mathrm{Yb} 2\end{array}$ & $58.353(8)$ \\
\hline 4 & $\begin{array}{l}\angle \mathrm{Yb} 1-\mathrm{Yb} 2- \\
\mathrm{Yb} 1\end{array}$ & $66.432(17)$ & $\begin{array}{l}\angle \mathrm{Yb} 1-\mathrm{Yb} 1- \\
\mathrm{Yb} 2\end{array}$ & $56.784(8)$ & $\begin{array}{l}\angle \mathrm{Yb} 1-\mathrm{Yb} 1- \\
\mathrm{Yb} 2\end{array}$ & $56.784(8)$ \\
\hline
\end{tabular}

\section{Powder X-ray diffraction (PXRD)}

Powder X-ray diffraction (PXRD) patterns were obtained with a PANalytical X'Pert PRO Alpha-1 diffractometer using $1.8 \mathrm{~kW}$ Ceramic copper tube source. The simulations of PXRD patterns from SCXRD results are performed by software CrystalDiffract 6 .

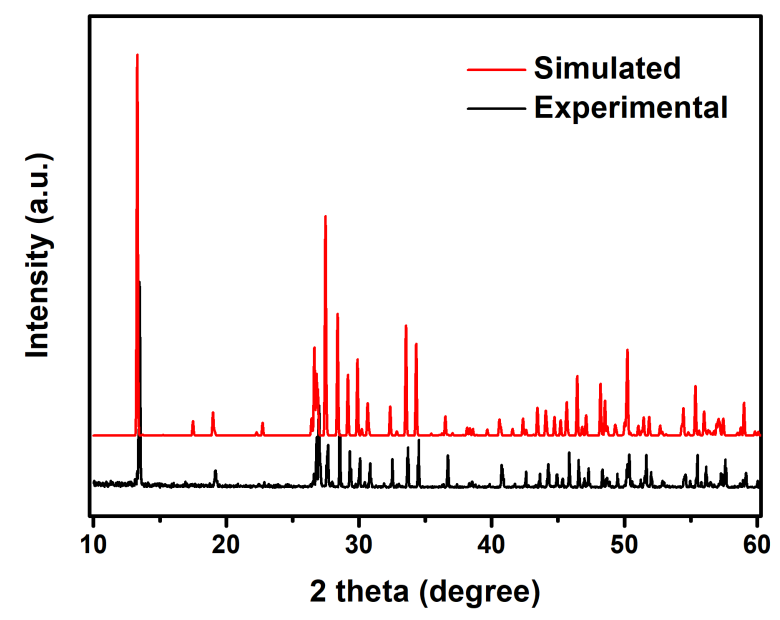

Figure S4. Experimental (black line) and the simulated (red line, simulated from singlecrystal X-ray result) powder X-ray diffraction patterns for 1-Yb. No obvious difference between the position of peaks is observed which demonstrates the bulk purity of assynthesized compound. 


\section{Fourier-transformation infrared spectroscopy (FT-IR)}

Fourier-transformation infrared (FT-IR) spectroscopy of 1-Yb was acquired in powders form on a Bruker ALPHA FTIR spectrometer from 400 to $4000 \mathrm{~cm}^{-1}$. The sample was dried under vacuum using Schlenk techniques for two hours prior to the FT-IR measurement.

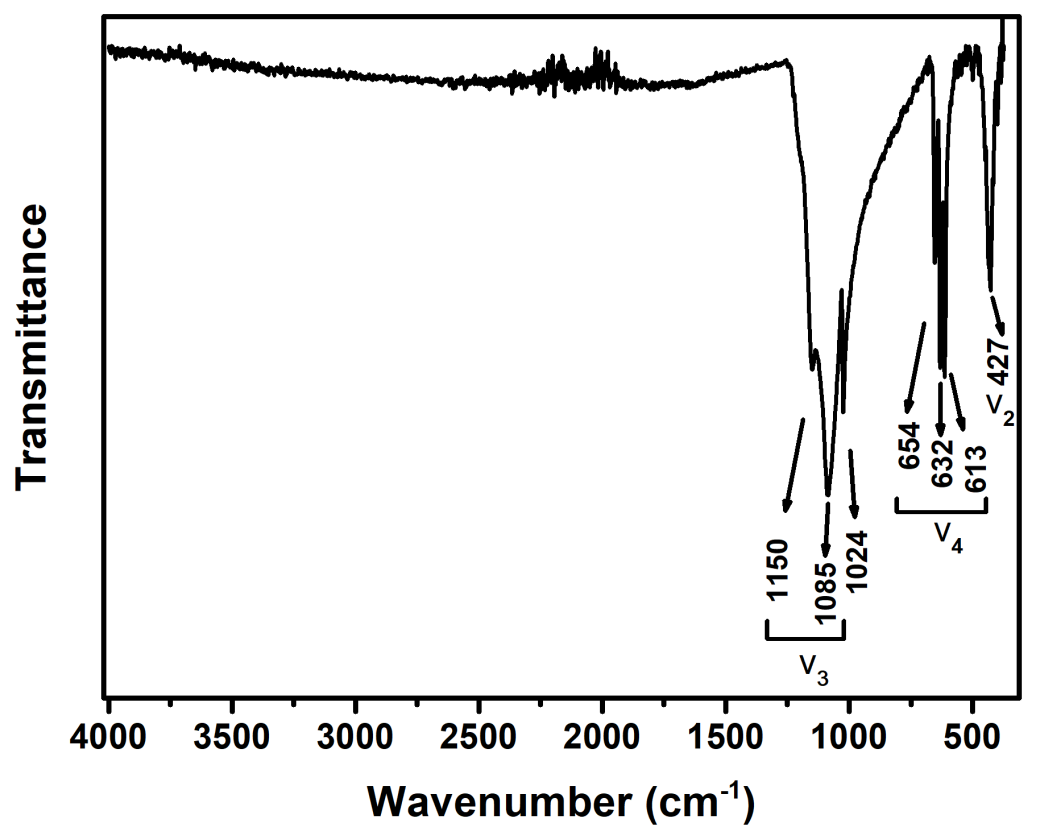

Figure S5. FT-IR results for $1-\mathrm{Yb}$. No obvious peak was observed from $3600 \mathrm{~cm}^{-1}$ to $2700 \mathrm{~cm}^{-1}$ which ruled out the existence of water or hydroxy group in $1-\mathrm{Yb}$. The IR vibrations of $\mathrm{SO}_{4}{ }^{2-}$ are documented to be located around $451\left(\mathrm{v}_{2}\right), 618\left(\mathrm{v}_{4}\right), 981\left(\mathrm{v}_{1}\right)$ and $1104\left(\mathrm{v}_{3}\right) \mathrm{cm}^{-1}$, and when the $\mathrm{SO}_{4}{ }^{2-}$ tetrahedron is distorted, both $\mathrm{v}_{3}$, and $\mathrm{v}_{4}$ vibrations could have two or three peaks and $v_{1}$ and $v_{2}$ could be active. ${ }^{4}$ The $v_{2}, v_{3}$, $\mathrm{V}_{4}$, vibrations of sulfate groups were clearly observed in $1-\mathrm{Yb}$ with $\mathrm{V}_{3}$ and $\mathrm{V}_{4}$ are split into two and three peaks, respectively. The peak centered at $1024 \mathrm{~cm}^{-1}$ could be the active $\mathrm{v}_{1}$ vibration mode since a large shoulder area can be observed. Therefore, the IR spectrum further validates the SCXRD results of $1-Y b$. 


\section{Physical property measurements}

Magnetic susceptibility measurements and isothermal magnetization measurements $\mathrm{M}(\mathrm{H})$ were performed on the 1-Yb using a Quantum Design physical property measurement system (PPMS) vibrating sample magnetometer (VSM) in a range of magnetic fields $0 \leq \mu_{0} \mathrm{H} \leq 5.5 \mathrm{~T}$ and temperatures $1.8 \leq \mathrm{T} \leq 300 \mathrm{~K}$. The reported ESD's are based on the linear fit and do not reflect underlying experimental error. Heatcapacity measurements were carried out on a Quantum Design physical property measurement system (PPMS) instrument in a range of measuring magnetic fields, $0 \leq$ $\mu_{0} \mathrm{H} \leq 1 \mathrm{~T}$ and temperatures $0.1 \leq \mathrm{T} \leq 4 \mathrm{~K}$. To ensure sample thermalization at low temperatures, powder measurements were made on pellets of 1-Yb mixed with silver powder, the contribution of which was measured separately and subtracted to obtain the specific heat $C_{p}$.

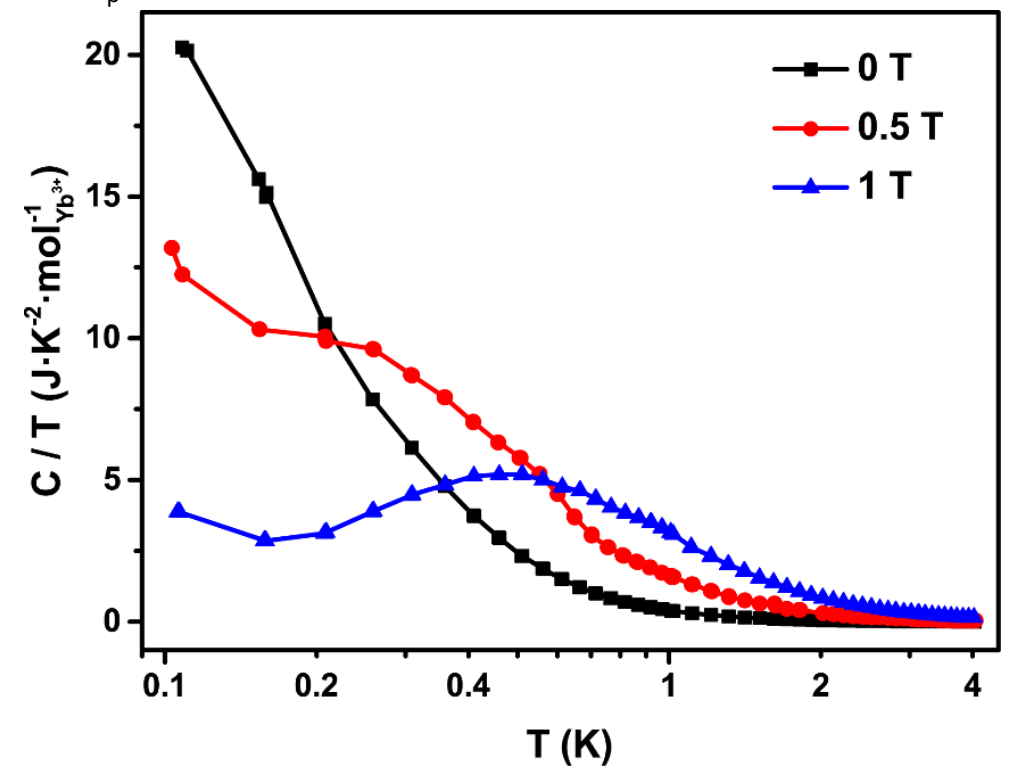

Figure S6. The temperature dependence of specific heat divided by temperature under different magnetic field in 1-Yb.

\section{References}

1. Sheldrick, G. M., Program for empirical absorption correction of area detector data. SADABS 1996.

2. Sheldrick, G. M., A short history of SHELX. Acta Crystallographica Section A: Foundations of Crystallography 2008, 64 (1), 112-122.

3. Sheldrick, G. M., Crystal structure refinement with SHELXL. Acta Crystallographica Section C: Structural Chemistry 2015, 71 (1), 3-8.

4. Wang, X.; Li, J.-G.; Molokeev, M. S.; Wang, X.; Liu, W.; Zhu, Q.; Tanaka, H.; Suzuta, K.; Kim, B.-N.; Sakka, Y., Hydrothermal crystallization of a $\mathrm{Ln}_{2}(\mathrm{OH})_{4} \mathrm{SO}_{4} \cdot \mathrm{nH}_{2} \mathrm{O}$ layered compound for a wide range of $\operatorname{Ln}(\mathrm{Ln}=\mathrm{La}-\mathrm{Dy})$, thermolysis, and facile transformation into oxysulfate and oxysulfide phosphors. RSC Advances 2017, 7 (22), 13331-13339. 